\title{
LAPAROSCOPY VERSUS LAPAROTOMY IN THE REPAIR OF VENTRAL HERNIAS: systematic review and meta-analysis
}

\author{
Paula Marcela Vilela CASTRO'1, Janayna Thainá RABELATO', \\ Gustavo Gomes Ribeiro MONTEIRO'1, Guilherme Ciconelli del GUERRA'1, \\ Mônica MAZZURANA2, 3 and Guines Antunes ALVAREZ2,3
}

\begin{abstract}
Objective - To compare the laparotomy and laparoscopy techniques for correction of ventral hernia when related to perioperative complications, length of hospitalization, surgical time, and recurrence of hernia. Methods - This was a systematic review of randomized controlled trials, which included studies retrieved from four databases (MEDLINE, Embase, Cochrane and LILACS), using a combination of the terms (Hernia, Ventral) and (Laparoscopy) and (Laparotomy). Results - Six randomized trials were included, totaling 566 patients, 283 in the Laparoscopy group and 283 in the Laparotomy group. Laparoscopy reduced the risk of infection of the surgical wound (NNT $=5)$ and seroma formation (NNT $=13)$ and less length hospitalization $(P=0.02)$ compared to laparotomy in the correction of ventral hernias. Furthermore, laparoscopy increased the incidence of enterotomy $(\mathrm{NNH}=25)$ and post operative pain $(\mathrm{NNH}=8)$ and longer surgical time $(P=0.0009)$ when compared with laparotomy. There was no difference related to abscess $(P=0.79)$, hematoma $(P=0.43)$ and recurrency of ventral hernias $(P=0.25)$. Conclusion - In the correction of ventral hernias, the use of laparoscopic technique is effective to reduce infections of the surgical wound and seroma formation, as well as, decrease the length hospitalization.
\end{abstract}

HEADINGS - Ventral hernia. Laparoscopy. Laparotomy. Review.

\section{INTRODUCTION}

The Center of Disease Control estimates that approximately five million Americans have ventral hernias ${ }^{(5)}$. It's an abdominal hernia that includes incisional, umbilical, epigastric, and Spiegel hernias and excludes inguinal, pelvic, and diaphragmatic hernias $^{(14)}$.

In the United States of America, approximately four hundred thousand patients undergo ventral hernia correction each year, because it is a common complication after abdominal surgery, ranging from $3 \%$ to $13 \%$. The incidence increases to $80 \%$ when associated to infection of the surgical wound ${ }^{(10)}$.

The repairing of ventral hernias continue to be a challenge for the surgeons due to high rate of recurrence $(31 \% \text { to } 54 \%)^{(12)}$. The use of mesh significantly reduces the recurrence rate by less than $10 \%$. However, the wide dissection of tissues for the placing of the mesh, increases the incidence of surgical infections and other related complications by $12 \%{ }^{(12)}$.

The laparoscopy treatment of the ventral hernia earned space in actual debates among surgeons, mainly, related to the techniques and the indication for this type of surgery ${ }^{(4)}$. In 1993, Le Blanc and Booth were the first to describe the laparoscopic access for ventral hernia. Since then, this way was considered an alternative technique for laparotomy ${ }^{(10)}$.

The present review has the purpose to analyze and compare the laparotomy and laparoscopy techniques for correction of ventral hernia when related to perioperative complications, length of hospitalization, surgical time, and recurrence of hernia.

\section{METHODS}

\section{Identification and selection of studies}

A search of electronic literature was done across the data bases MEDLINE, EMBASE, COCHRANE, and LILACS. Across MEDLINE, utilizing the combination of terms: (Hernia, Ventral) and (Laparoscopy) and (Laparotomy). On EMBASE, we utilize the following search strategy: (Ventral hernia) and (Laparoscopy) and (Laparotomy). On LILACS, the keywords used were: (Ventral hernia) and (Laparoscopy) and (Laparotomy). On COCHRANE: (Ventral hernia)

\footnotetext{
Declared conflict of interest of all authors: none

${ }^{1}$ Faculdade de Medicina do Centro Universitário Lusíada - UNILUS; ${ }^{2}$ Departamento de Clínica Cirúrgica do Centro Universitário Lusíada, ${ }^{3}$ Departamento de Cirurgia Geral do Hospital Guilherme Álvaro, Santos, SP, Brasil.

Correspondence: Mônica Mazzurana. Centro Universitário Lusíada - UNILUS. Avenida Pinheiro Machado, 121. Santos, SP, Brasil. E-mail: mazzu@uol.com.br
} 
and (Laparoscopy) and (Laparotomy). Manual searches were done among study references found. The searches ended on June 7, 2013.

The articles were selected independently and in pairs, by reading the titles and abstracts. Any difference between the articles was resolved by consensus.

\section{Criteria of inclusion and exclusion}

The criteria of inclusion utilized consists of the following: Randomized clinical trials comparing the laparoscopy and laparotomy on ventral hernia; despite the language.

The criteria of exclusion are: strangulation, incarceration, patient ASA 4 or 5, intestinal obstruction, perforation, peritonitis, emergency operation, participating patient in other clinical trials, non-randomized clinical trials, controlled case and cohort studies.

\section{Analyzed outcomes}

The analyzed outcomes were length of hospitalization, surgical time, recurrency of hernia, and perioperative complications, such as: infection of the surgical site, seroma, hematoma, post-operative pain, and enterotomy.

\section{Methodological quality}

The methodological quality of the primary study was evaluated by GRADE system, which was proposed by the group Grades of Recommendation, Assessment, Development and Evaluation ${ }^{(2)}$.

\section{Statistic analysis}

The meta-analysis was performed with the Review Manager 5.2 program. Data were evaluated by intention-to-treat, meaning the patients that did not undergo the proposed intervention or patients lost in follow-up during the study were considered as clinical outcomes.

The evaluation of the dichotomic variables was performed by the difference in absolute risk (RD) adopting a $95 \%$ confidence interval (CI). When there was a statistically significant difference between the groups, the number needed to treat $(\mathrm{NNT})$ or the number needed to cause harm $(\mathrm{NNH})$ was calculated.

The continuous variables were evaluated by the difference in means (MD). Studies that did not show data in terms of means and their respective standard deviations were not included in the analyses.

\section{Heterogeneity and sensitivity analysis}

Inconsistencies among the clinical studies were estimated using the chi-squared heterogeneity test and quantified using $\mathrm{I}^{2}$. A value above $50 \%$ was considered substantial. Studies that generated heterogeneity were represented by funnel plots.

\section{RESULTS}

\section{Selection of studies}

In total, 180 trials were eligible $($ MEDLINE $=110$, EMBASE $=64$, COCHRANE $=4$, and LILACS $=2$ ) by electronic searches. In the manual search no articles were found in addition to those previously selected. Initially 172 articles were excluded because they were not randomized clinical trials, they were cohort trials, controlled case, and non-randomized clinical trials. Eight articles were pre selected and two of them belonged to the same study. Therefore, this review included six randomized clinical trials (Figure 1).

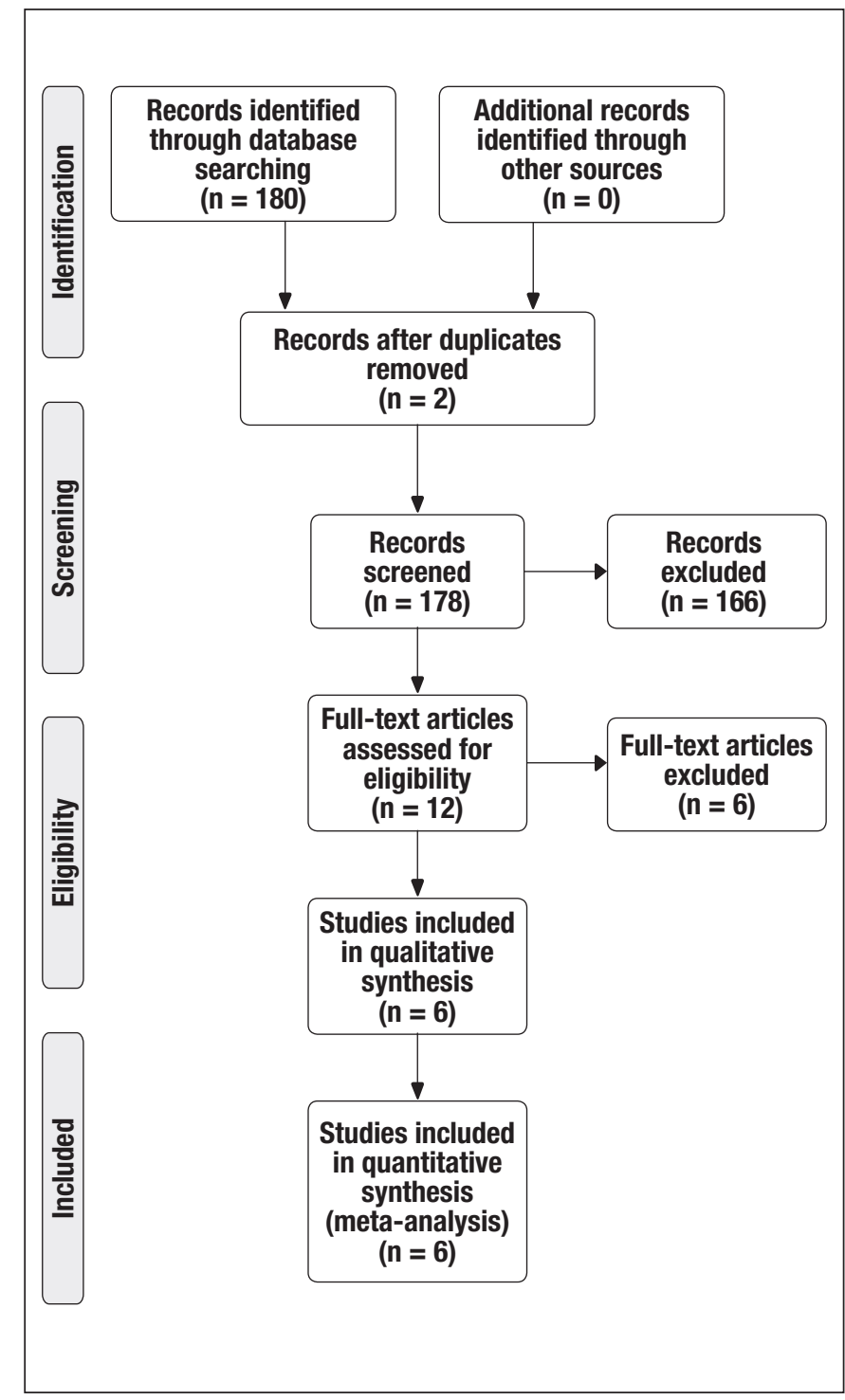

FIGURE 1. Algorithm of the search for articles in literature. PRISMA adapted $^{(13)}$. n: number of articles

The six studies included randomized the patients in two groups: laparotomy and laparoscopy, totalizing 566 patients, with 283 in the laparotomy group and 283 in the laparoscopy group.

Methodological quality evaluation performed by GRADE is represented on Figure 2. 


\begin{tabular}{|c|c|c|c|c|c|c|}
\hline Evaluated Parameters & Carbajo $\mathbf{M A}^{(3)}$ & Barbaros $\mathrm{U}^{(1)}$ & Itani $\mathbf{K M}^{(8)}$ & Misra $\mathrm{MC}^{(12)}$ & Eker $\mathbf{H H}^{(6)}$ & Pring $\mathrm{CM}^{(16)}$ \\
\hline Whas the study randomized? & $\mathrm{Y}$ & $\mathrm{Y}$ & $\mathrm{Y}$ & $\mathrm{Y}$ & $\mathrm{Y}$ & $\mathrm{Y}$ \\
\hline $\begin{array}{l}\text { Was the allocation of patients to the groups } \\
\text { confidential? }\end{array}$ & ND & ND & $\mathrm{Y}$ & $\mathrm{Y}$ & $\mathrm{Y}$ & $\mathrm{Y}$ \\
\hline $\begin{array}{l}\text { Were the patients analysed in the groups to } \\
\text { which they were randomized (was the analysis } \\
\text { by intention-to-treat)? }\end{array}$ & $\mathrm{Y}$ & $\mathrm{Y}$ & $\mathrm{Y}$ & $\mathrm{Y}$ & $\mathrm{Y}$ & $\mathrm{Y}$ \\
\hline $\begin{array}{l}\text { Were the patients from the groups similar as to } \\
\text { previously known prognostic factors? }\end{array}$ & $\mathrm{Y}$ & $\mathrm{Y}$ & $\mathrm{Y}$ & $\mathrm{Y}$ & $\mathrm{Y}$ & $\mathrm{Y}$ \\
\hline Was the study blind? & $\mathrm{N}$ & $\mathrm{N}$ & $\mathrm{N}$ & $\mathrm{Y}$ & $\mathrm{N}$ & $\mathrm{N}$ \\
\hline $\begin{array}{l}\text { Except for the experimental intervention, were } \\
\text { the groups treated equally? }\end{array}$ & $\mathrm{Y}$ & $\mathrm{Y}$ & $\mathrm{Y}$ & $\mathrm{Y}$ & $\mathrm{Y}$ & $\mathrm{Y}$ \\
\hline Were the losses significant? & $\mathrm{N}$ & ND & $\mathrm{N}$ & $\mathrm{N}$ & $\mathrm{N}$ & $\mathrm{N}$ \\
\hline $\begin{array}{l}\text { Did the study have a precision estimate for the } \\
\text { effects of treatment? }\end{array}$ & $\mathrm{Y}$ & $\mathrm{Y}$ & $\mathrm{Y}$ & $\mathrm{Y}$ & $\mathrm{Y}$ & $\mathrm{Y}$ \\
\hline $\begin{array}{l}\text { Are the study patients similar to those of } \\
\text { interest? }\end{array}$ & $\mathrm{Y}$ & $\mathrm{Y}$ & $\mathrm{Y}$ & $\mathrm{Y}$ & $\mathrm{Y}$ & $\mathrm{Y}$ \\
\hline $\begin{array}{l}\text { Are the outcomes of the study clinically } \\
\text { relevant? }\end{array}$ & $\mathrm{Y}$ & $\mathrm{Y}$ & $\mathrm{Y}$ & $\mathrm{Y}$ & $\mathrm{Y}$ & $\mathrm{Y}$ \\
\hline Were the potential conflicts of interest declared? & ND & ND & ND & ND & ND & ND \\
\hline
\end{tabular}

FIGURE 2. Methodological evaluation by GRADE. Y: Yes, N: No, ND: Not described

\section{Description of the studies included}

The Barbaros et al. ${ }^{(1)}$ trial is a prospective study that was conducted between 2001 and 2005 and included 46 patients with ventral hernias (primary and incisional). This patients were randomized in two groups: 23 patients in the laparoscopy group and 23 patients in the laparotomy group. The length of hospitalization, surgical time, and perioperarative complications (paralytic ileus, enterotomy, seroma, hematoma, and infection of the surgical wound) were the evaluated outcomes.

In the Carbajo et al. ${ }^{(3)}$ trial, 60 patients with ventral hernia were randomized in two groups of 30 patients each, laparotomy and laparoscopy. The evaluated outcomes were incarceration, seroma, abscesses, hematoma, phlebitis, cellulitis, and skin necrosis. The study was conducted between 1994 and 1997.

Eker at al. ${ }^{(6)}$ is a multicentric randomized prospective trial conducted between 1999 and 2006. In which, 194 patients were evaluated, 94 in the laparoscopy group and 100 in the laparotomy group. Surgical time and perioperative complications (enterotomy, infection, hematoma, seroma, post operative pain, phlebitis, paralytic ileus, and bleeding) was considered.

Itani et al.$^{(8)}$ is a multicentric randomized trial conducted conducted between 2004 and 2007 and included 146 patients with incisional ventral hernia. In each group they selected 73 patients for laparotomy and 73 patients for laparoscopy.
Length of hospitalization, infection, hematoma, bleeding, abscess, paralytic ileus, seroma, and skin necrosis, were the outcomes analyzed in this study.

Misra et al. ${ }^{(12)}$ is a prospective randomized trial conducted between 2003 and 2005 which included 66 patients with incisional and primary ventral hernias. Both laparotomy and laparoscopy groups included 33 patients. The outcome observed in this study was hernia recurrency, infection of the surgical wound, necrosis, paralytic ileus, seroma, and post operative pain.

On Pring et al. ${ }^{(16)} 54$ patients with ventral hernia (primary and incisional) were randomized in two groups. The laparoscopy group had 30 patients while the laparotomy group had 24 patients. Surgical time and perioperative complications such as infection of the surgical wound, seroma, and abscess were evaluated. This study was conducted between 2003-2005.

\section{Perioperative infection}

Four primary trials analyzed the perioperative infection outcome. The incidence of infection was $4.4 \%$ in the laparoscopy group (7 of 159 patients) and $23.53 \%$ in the laparotomy group ( 36 of 153 patients). Laparoscopy reduced the absolute risk of infection in $19 \%$ (CI 95\% -0.26 to $-0.12 ; P<0.00001$; $\mathrm{I}^{2}=0 \%$ ), with five patients needing treatment in order to achieve this benefit $(\mathrm{NNT}=5)($ Table 1$)$. 
TABLE 1. Meta-analysis of the incidence of Infection between Laparoscopy and Laparotomy

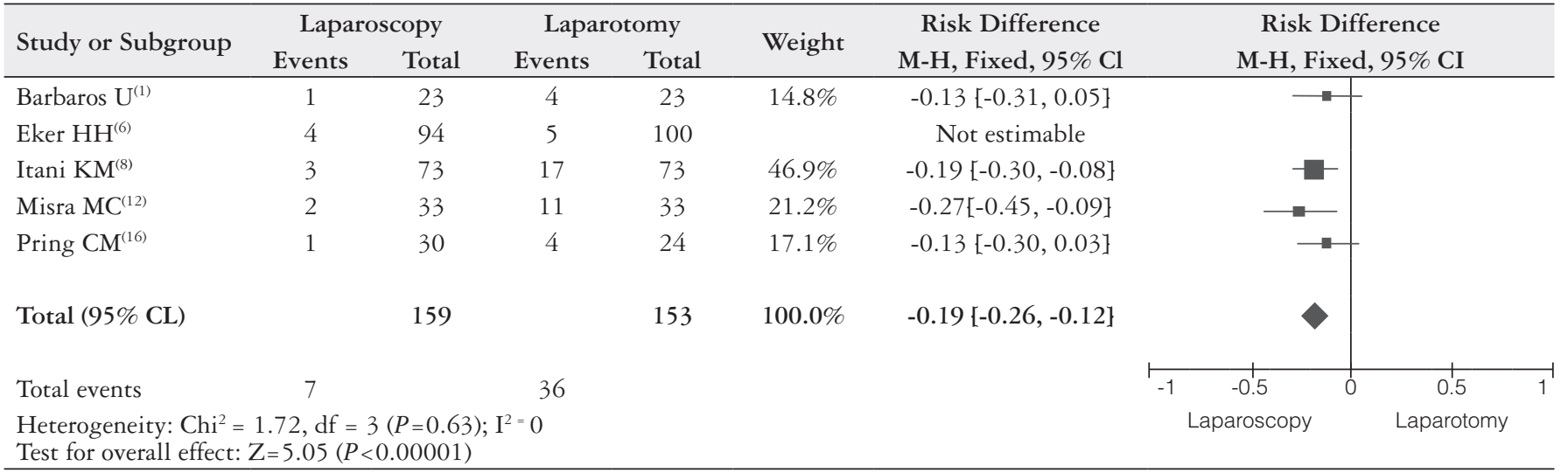
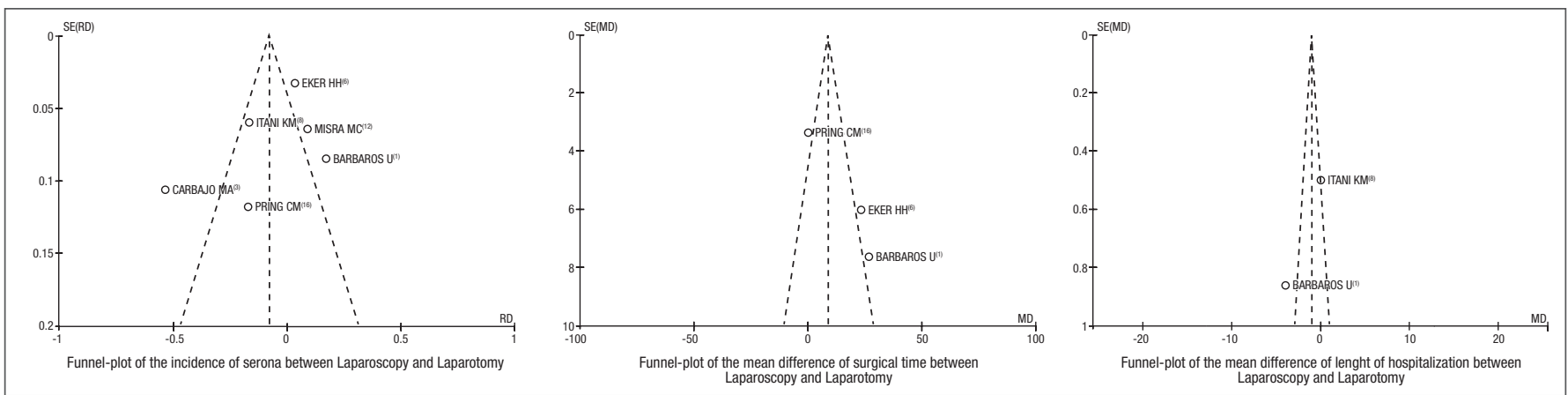

FIGURE 3. Funnel-plots of the outcomes that presented heterogeneity above than $50 \%$

Each one of the funnel-plots of outcomes analyzed are represented in Figure 3.

\section{Seroma}

Six of the primary trials analyzed seroma formation as an outcome. The incidence of seroma formation was $10.6 \%$ in the laparoscopy group ( 30 of 283 patients) and $18.02 \%$ in laparotomy group (51 of 283 patients). Laparoscopy reduced the absolute risk of infection in $8 \%$ (CI $95 \%-0.13$ to -0.03 ; $P=0.004 ; \mathrm{I}^{2}=90 \%$ ), with 13 patients needing treatment in order to achieve this benefit $(\mathrm{NNT}=13)$ (Table 2).

\section{Abscess}

Three of the primary trials analyzed abscess as an outcome. The incidence was $4.51 \%$ in the laparoscopy group (6 of 133 patients) and 3.94\% in the laparotomy group (5 of 127 patients). There was no statistical difference between the two groups (RD 0.01; CI 95\% -0.04 to 0.06; $P=0.79 ; \mathrm{I}^{2}=0 \%$ ).

\section{Hematoma}

Four of the primary trials analyzed hematoma as an outcome. The incidence was $6.36 \%$ in the laparoscopy group (14 of 220 patients) and $8.41 \%$ in the laparotomy group (19 of 226

TABLE 2. Meta-analysis of the incidence of seroma between Laparoscopy and Laparotomy

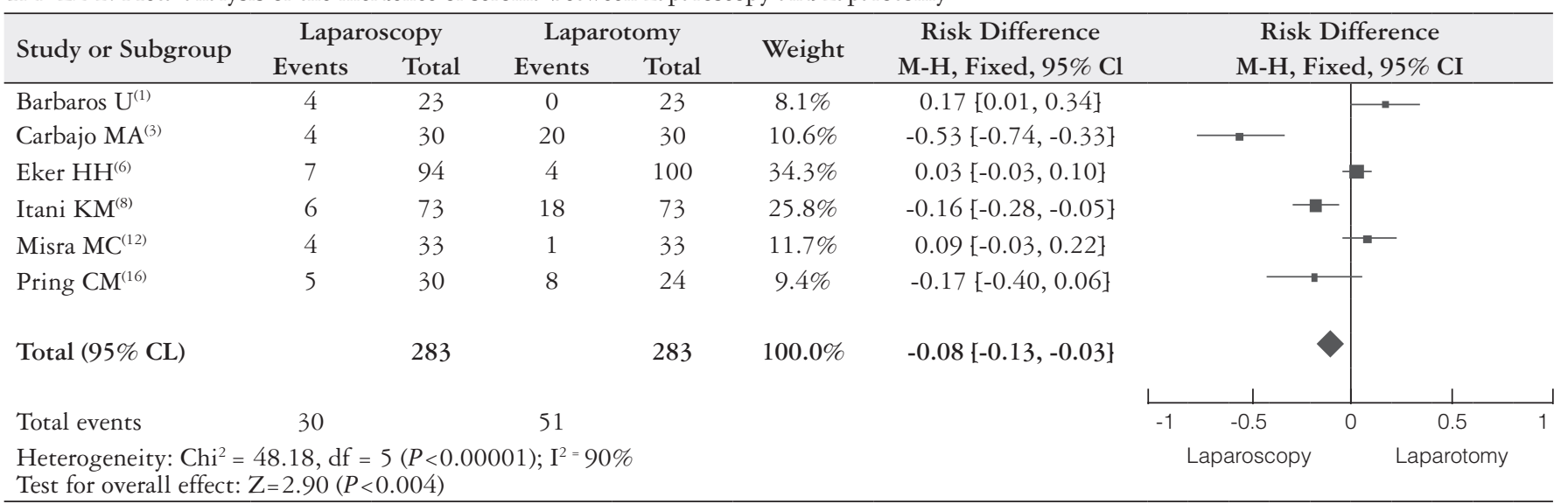


patients). No statistical significance was found between the two groups (RD -0.02; CI 95\% -0.07 to $0.03 ; P=0.43 ; \mathrm{I}^{2}=43 \%$ ).

\section{Enterotomy}

Three of the primary trials analyzed enterotomy as an outcome. The incidence of enterotomy was $4.74 \%$ in the laparoscopy group (9 of 190 patients) and $0.51 \%$ in the laparotomy group ( 1 of 196 patients). Laparotomy reduces the absolute risk of infection in 4\% (CI 95\% 0.01 to $0.08 ; P$ $=0.02 ; \mathrm{I}^{2}=0 \%$ ), with 25 patients needing treatment in order to achieve this benefit $(\mathrm{NNT}=25)($ Table 3$)$.

\section{Postoperative pain}

Two of the primary trials analyzed postoperative pain as an outcome. The incidence of postoperative pain was $14.17 \%$ in the laparoscopy group (18 of 127 patients) and $2.25 \%$ in the laparotomy group ( 3 of 133 patients). Laparotomy reduces the absolute risk of infection in $12 \%$ (CI $95 \% 0.05$ to 0.19 ; $\left.P=0.0005 ; \mathrm{I}^{2}=0 \%\right)$, with eight patients needing treatment in order to achieve this benefit $(\mathrm{NNT}=8)($ Table 4$)$.

\section{Hernia recurrency}

Five trials analyzed recurrency of hernia. The incidence of hernia recurrency was $11.55 \%$ in the laparoscopy group ( 29 of 251 patients) and $8.8 \%$ in the laparotomy group (22 of 250 patients). No statistical significance was found between the groups (RD $0.03 ;$ CI $95 \%-0.02$ to $0.08 ; P=0.25 ; \mathrm{I}^{2}=0 \%$ ).

\section{Surgical time}

Three trials analyzed surgical time as an outcome. The mean difference between the two groups was 9.21 (CI $95 \% 3.79$ to $14.63 ; P=0.0009$ and $\mathrm{I}^{2}=88 \%$ ). Therefore, laparotomy presented reduced surgical time as compared to laparotomy (Table 5).

TABLE 3. Meta-analysis of the incidence of enterotomy between Laparoscopy and Laparotomy

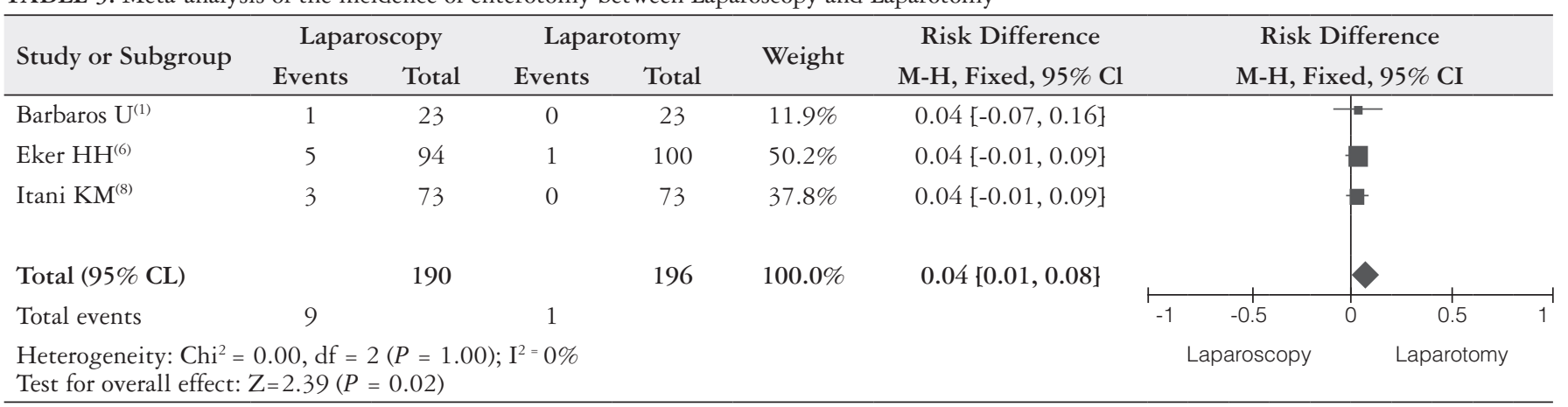

TABLE 4. Meta-analysis of the incidence of postoperative pain between Laparoscopy and Laparotomy

\begin{tabular}{|c|c|c|c|c|c|c|c|c|c|c|c|}
\hline \multirow{3}{*}{$\begin{array}{l}\text { Study or Subgroup } \\
\text { Eker } \mathrm{HH}^{(6)}\end{array}$} & \multicolumn{2}{|c|}{ Laparoscopy } & \multicolumn{2}{|c|}{ Laparotomy } & \multirow{3}{*}{$\begin{array}{l}\text { Weight } \\
74.6 \%\end{array}$} & \multirow{3}{*}{$\begin{array}{c}\text { Risk Difference } \\
\text { M-H, Fixed, 95\% Cl } \\
0.13[0.06,0.20]\end{array}$} & \multirow{2}{*}{\multicolumn{5}{|c|}{$\begin{array}{c}\text { Risk Difference } \\
\text { IV, Fixed, 95\% CI }\end{array}$}} \\
\hline & \multirow{2}{*}{$\begin{array}{c}\text { Events } \\
12\end{array}$} & \multirow{2}{*}{$\begin{array}{c}\text { Total } \\
94\end{array}$} & \multirow{2}{*}{$\begin{array}{c}\text { Events } \\
0\end{array}$} & \multirow{2}{*}{$\frac{\text { Total }}{100}$} & & & & & & & \\
\hline & & & & & & & & & & & \\
\hline Total $(95 \% \mathrm{CL})$ & & 127 & & 133 & $100.0 \%$ & $0.12\{0.05,0.19\}$ & & & & & \\
\hline
\end{tabular}

TABLE 5. Meta-analysis of mean difference of surgical time between Laparoscopy and Laparotomy

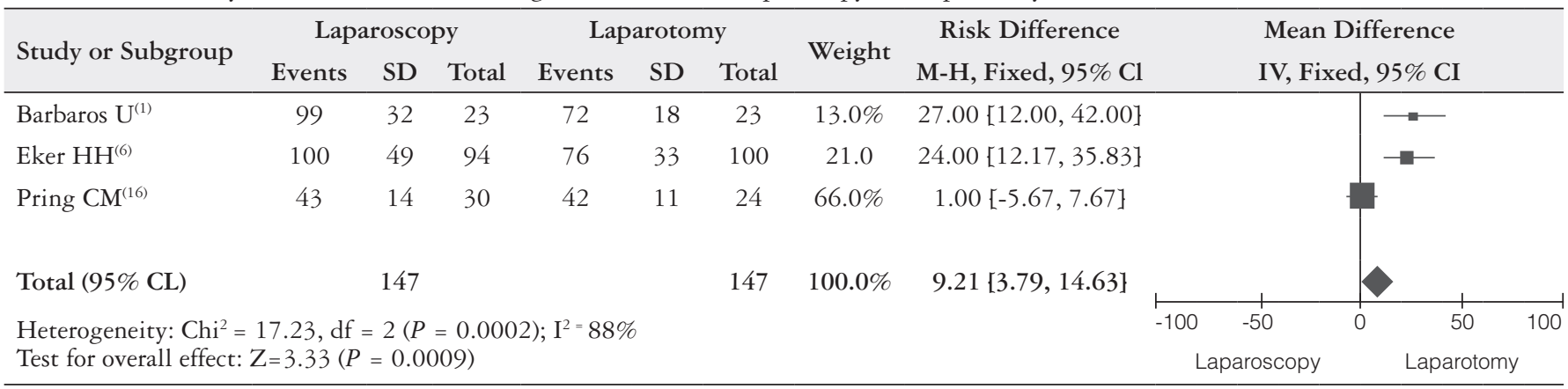




\section{Length of hospitalization}

Two trials analyzed length of hospitalization. The mean difference between of the groups was 1.00 (CI 95\% - 1.84 to $-0.16 ; P=0.02$ and $\mathrm{I}^{2}=94 \%$ ). Which means, laparoscopy reduced the length of hospitalization compared to laparotomy (Table 6). time, because they often are asymptomatic they should not be classified as a complication unless the seroma is symptomatic or does not self-resolve after 4 to 6 weeks of surgery. Postoperative pain is also significantly less in the laparoscopic group in the meta-analysis for Sajid et al. Howerever, Sauerland et al. shows less pain in the laparotomy group, as in our result.

TABLE 6. Meta-analysis of mean difference of length of hospitalization between Laparoscopy and Laparotomy

\begin{tabular}{|c|c|c|c|c|c|c|c|c|c|c|c|c|c|}
\hline \multirow{3}{*}{$\begin{array}{l}\text { Study or Subgroup } \\
\text { Barbaros } U^{(1)}\end{array}$} & \multicolumn{3}{|c|}{ Laparoscopy } & \multicolumn{3}{|c|}{ Laparotomy } & \multirow{2}{*}{ Weight } & \multirow{2}{*}{$\begin{array}{c}\text { Risk Difference } \\
\text { M-H, Fixed, } 95 \% \mathrm{Cl}\end{array}$} & \multirow{2}{*}{\multicolumn{5}{|c|}{$\begin{array}{l}\text { Mean Difference } \\
\text { IV, Fixed, 95\% CI }\end{array}$}} \\
\hline & \multirow{2}{*}{ Events } & \multirow{2}{*}{$\frac{\mathrm{SD}}{1}$} & \multirow{2}{*}{$\frac{\text { Total }}{23}$} & \multirow{2}{*}{$\frac{\text { Events }}{6}$} & \multirow{2}{*}{$\frac{\mathrm{SD}}{4}$} & \multirow{2}{*}{$\begin{array}{c}\text { Total } \\
23\end{array}$} & & & & & & & \\
\hline & & & & & & & 25.0 & $-4.00\{-5.69,-2.31]$ & & & & & \\
\hline Itani $\mathrm{KM}^{(8)}$ & 4 & 3 & 73 & 4 & 3 & 73 & 75.0 & $0.00[-0.97,0.97]$ & & & & & \\
\hline Total $(95 \% \mathrm{CL})$ & & 96 & & & & 96 & $100.0 \%$ & $-1.00[-1.84,-0.16]$ & & & $\Delta$ & & \\
\hline Heterogeneity: Chi $^{2}=$ & $16.23, \mathrm{df}$ & $1(P$ & 0.0001 & $; \mathrm{I}^{2}=94 \%$ & & & & & -20 & -10 & 0 & 10 & 20 \\
\hline Test for overall effect: & $\mathrm{L}=2.33(\mathrm{I}$ & $=0.0$ & & & & & & & & osco & & Lapar & \\
\hline
\end{tabular}

\section{DISCUSSION}

Systematic review and meta-analysis is a type of study of scientific accuracy for selecting the best available evidence in the medical literature, however we must evaluate the methodological quality of the primary trails. This is the most important characteristic to obtaining accurate conclusions about the effect of interventions. To avoid statistic biases we decided to include only results with clinical and statistical homogeneity.

In medical literature there are three review with metaanalysis: Sajid ${ }^{(17)}$, Sauerland ${ }^{(18)}$ and Forbes ${ }^{(7)}$ that evaluate surgical treatment of ventral hernias. However, none of them included only randomized clinical trials and for this reason, it can lead to bias, related to meta analysis results. Thus, justifies the need for further systematic review with meta-analysis with greater methodological rigor in the selection of the studies analyzed, including only randomized controlled trials.

As laparoscopic ventral hernia repair is a relatively new surgical technique and with a potential for serious complications, the post-operative complications are an important outcome parameter to be recorded ${ }^{(15)}$. However it is difficult to compare the results from different studies in the literature because they usually lack a description of the severity of the complications. For this reason, the most frequent complications were analyzed.

The lower risk of wound infection after laparoscopic ventral hernia repair is fully in line with other laparoscopic techniques, such as cholecystectomy or appendectomy. The three meta-analysis from Sajid et al., Sauerland et al. and Forbes et al. were unanimous in this regard. When compared abscess and hematoma, no statistical difference between the two groups analysed, as in the studies cited above.

Previous results after incisional hernia repair remain disappointing with high recurrence rates. This meta-analysis not found statistical significance of recurrence after both procedures, as well as Forbes et al.

Most surgeons report postoperative seromas. In the mean-
The present study was consistent with a number of prior studies in indicating that length of hospital stay after a laparoscopic repair and surgical time is shorter than that after an open surgery, and the results for Sajid et al. and Forbes et al.

Another very important point that was not addressed in any study was obesity. A retrospective cohort ${ }^{(11)}$ with 47.661 patients were selected from the Nationwide Inpatient Sample database showed that laparoscopy was associated with a fewer overall complication rate and lower mean total hospital charges.

In this review, the Jadad Scale ${ }^{(9)}$ was not used for the clinical evaluation of the methodological quality of all the trials because this scale outlines the blinding of the studies. Its acknowledged that in some surgical trials, specifically on those which compares laparotomic and laparoscopic techniques, that it is not possible to use the blinding method of surgeons. As a consequence, the maximum on Jadad Scale would be 3 , which would cause limitation in the selection of the inclusion of trials.

One possible source of bias cause would be on the discrepancy of the randomizing processes during the chosen trials. However the quality of the randomized allocation was considered ideal in every trial chosen. All patients analysed had a very well defined specific eligibility criteria. In the statistic analysis, the selection of the sample size and the analysis of intention to treat were used. A common limitation for the analysis of the duration of surgery and length hospitalization was the lack of statistical data including standard deviation or the presentation of continuous data as median or range.

The strategy of search stated that there were not many randomized controlled trials available comparing laparoscopy and laparotomy in the surgical treatment for ventral hernias.

The study followed the ethical and confidentiality principles of information that are recommended, since it is an analysis of results already published in other articles, and the formal approval of a research ethics committee was not necessary. 
In conclusion, laparoscopy is related to low incidence of infection of the surgical wound and seroma formation, in addition to that, less length hospitalization compared to laparotomy in the correction of ventral hernias. Nevertheless, laparoscopy demonstrated a high incidence of enterotomy and post operative pain, as well as longer surgical time when compared with laparotomy. No statistic significance was found related to abscess, hematoma and recurrency of ventral hernias.

Castro PMV, Rabelato JT, Monteiro GGR, Guerra GC, Mazzurana M, Alvarez GA. Laparoscopia versus laparotomia no reparo das hernias ventrais: revisão sistemática e meta-análise. Arq Gastroenterol. 2014,51(3):205-11.

RESUMO - Objetivo - Comparar as técnicas de laparoscopia e laparotomia para a correção de hérnia ventral quando relacionadas com as complicações perioperatórias, tempo de hospitalização, tempo cirúrgico e recorrência de hérnia. Métodos - Foi realizada uma revisão sistemática de ensaios clínicos randomizados, que incluiu estudos de quatro bases de dados (MEDLINE, Embase, Cochrane and LILACS) usando a combinação dos descritores (Hernia ventral) AND (Laparoscopia) AND (Laparotomia). Resultados - Seis ensaios clínicos randomizados foram incluídos, totalizando 566 pacientes, sendo 283 no grupo da Laparoscopia e 283 no grupo da Laparotomia. A laparoscopia reduziu o risco de infecção da ferida operatória $(\mathrm{NNT}=5)$ e a formação do seroma $(\mathrm{NNH}=13)$ além do tempo de hospitalização $(P=0,02)$ quando comparado à laparotomia para a correção de hérnias ventrais. Além disso, a laparoscopia aumentou a incidência de enterotomia $(\mathrm{NNH}=25)$, dor pós-operatória $(\mathrm{NNH}=8)$ e o tempo cirúrgico $(P=0,0009)$ quando comparado à laparotomia. Não houve diferença significantiva em relação ao abscesso $(P=0,79)$, hematoma $(P=0,43)$ e recorrência de hérnias ventrais $(P=0,25)$. Conclusão - Na correção de hérnias ventrais, o uso da técnica laparoscópica é efetiva para reduzir infecção de ferida operatória e a formação do seroma, assim como diminui o tempo de hospitalização.

DESCRITORES - Hérnia ventral. Laparoscopia. Laparotomia. Revisão.

\section{REFERENCES}

1. Barbaros U, Asoglu O, Seven R, Erbil Y, Dinccag A, Deveci U, et al. The comparison of laparoscopic and open ventral hernia repairs: a prospective randomized study. Hernia. 2007;11:1-6.

2. Brasil. Ministério da Saúde. Secretaria de Ciência, Tecnologia e Insumos Estratégicos. Departamento de Ciência e Tecnologia. Diretrizes metodológicas: elaboração de pareceres técnico-científicos. Brasília; Ministério da Saúde; 2011. p.79 tab (A. Normas e Manuais Técnicos).

3. Carbajo MA, Martín del Olmo JC, Blanco JI, de la Cuesta C, Toledano M, et al Laparoscopic treatment vs open surgery in the solution of major incisional and abdominal wall hernias with mesh. Surg Endosc. 1999;13:250-2.

4. Cuccurullo D, Piccoli M, Agresta F, Magnone S, Corcione F, Stancanelli V, Melotti G. Laparoscopic ventral incisional hernia repair: evidence-based guidelines of the first Italian Consensus Conference. Hernia. 2013;17:557-66.

5. Eid GM, Wikiel KJ, Entabi F, Saleem M. Ventral Hernias in Morbidly Obese Patients: A Suggested Algorithm for Operative Repair. Obes Surg. 2013;23:703-9.

6. Eker HH, Hansson BM, Buunen M, Janssen IM, Pierik RE, Hop WC, et al. Laparoscopic vs. open incisional hernia repair: a randomized clinical trial. JAMA Surg. 2013;148:259-63.

7. Forbes SS, Eskicioglu C, McLeod RS, Okrainec A. Meta-analysis of randomized controlled trials comparing open and laparoscopic ventral and incisional hernia repair with mesh. Br J Surg. 2009;96:851-8.

8. Itani KM, Hur K, Kim LT, Anthony T, Berger DH, Reda D, Neumayer L; Veterans Affairs Ventral Incisional Hernia Investigators. Comparison of laparoscopic and open repair with mesh for the treatment of ventral incisional hernia: arandomized trial. Arch Surg. 2010;145:322-8.
9. Jadad AR, Moore RA, Carroll D, Jenkinson C, Reynolds DJ, Gavaghan DJ, McQuay HJ. Assessing the quality of reports of randomized clinical trials: is blinding necessary? Control Clin Trials. 1996;17:1-12.

10. Kaoutzanis C, Leichtle SW, Mouawad NJ, Welch KB, Lampman RM, Cleary RK. Postoperative surgical site infections after ventral/incisional hernia repair: a comparison of open and laparoscopic outcomes. Surg Endosc. 2013;27:2221-30.

11. Lee J, Mabardy A, Kermani R, Lopez M, Pecquenex N, McCluney A. Laparoscopic vs open ventral hernia repair in the era of obesity. JAMA Surgery. 2013;148:723-6.

12. Misra MC, Bansal VK, Kulkarni MP, Pawar DK. Comparison of laparoscopic and open repair of incisional and primary ventral hernia: results of a prospective randomized study. Surg Endosc. 2006;20:1839-45.

13. Moher D, Liberati A, Tetzlaff J, Altman DG; PRISMA Group. Preferred reporting items for systematic reviews and meta-analyses: the PRISMA statement. BMJ. 2009;339:b2535.

14. Muysoms F, Campanelli G, Champault GG, DeBeaux AC, Dietz UA, Jeekel J. EuraHS: the development of an international online platform for registration and outcome measurement of ventral abdominal wall hernia repair. Hernia. 2012;16:239-50.

15. Olmi S, Scaini A, Cesana GC, Erba L, Croce E. Laparoscopic versus open incisional hernia repair. Surg Endosc. 2007;21:555-9.

16. Pring CM, Tran V, O'Rourke N, Martin IJ. Laparoscopic versus open ventral hernia repair: a randomized controlled trial. ANZ J Surg. 2008;78:903-6.

17. Sajid MS, Bokhari SA, Mallick AS, Cheek E, Baig MK. Laparoscopic versus open repair of incisional/ventral hernia: a meta-analysis. Am J Surg. 2009;197:64-72.

18. Sauerland S, Walgenbach M, Habermalz B, Seiler CM, Miserez M. Laparoscopic versus open surgical techniques for ventral or incisional hernia repais. Cochrane Database of Syst Rev. 2011:CD007781. 